\title{
Drawing out emotions in primary grade geometry: An analysis of participant-produced drawings of Grade 3-6 students
}

\author{
Ana Kuzle \\ University of Potsdam, Germany
}

Research on psychosocial classroom learning environments has a strong tradition due to the early discovery of a relationship between positive classroom climate and academic performance and motivation, engagement, participation, and attitude towards school and teaching. Yet, more research is needed in this area due to the rich concept of classroom climate. In this paper, I focus on the emotional classroom climate in specific mathematics lessons, namely geometry lessons. The goals of this paper are threefold: (a) to present an analytical tool to determine the emotional classroom climate in geometry lessons using participant-produced drawings, (b) to provide insight into the emotional classroom climate in primary grade geometry lessons (Grades 3-6), and (c) to report on the differences and similarities between the grade levels regarding the emotional classroom climate. In total, 114 German primary grade students participated in the study. The emotional classroom climate was analyzed using participant-produced drawings. The results showed that the emotional classroom climate in all grades could be described as positive and relatively stable. However, positive emotional classroom climate dominated in Grade 3 geometry lessons only. Negative classroom climate was elicited in very few cases, if at all. Still, an ambivalent classroom climate (both positive and negative emotions) increased from the lower to the higher grades. Lastly, versatile implications for theory and practice are discussed regarding the methodology as well as possible future directions.

KEYWORDS: Emotional classroom climate, geometry lessons, mathematicsrelated affect, participant-produced drawings, primary education

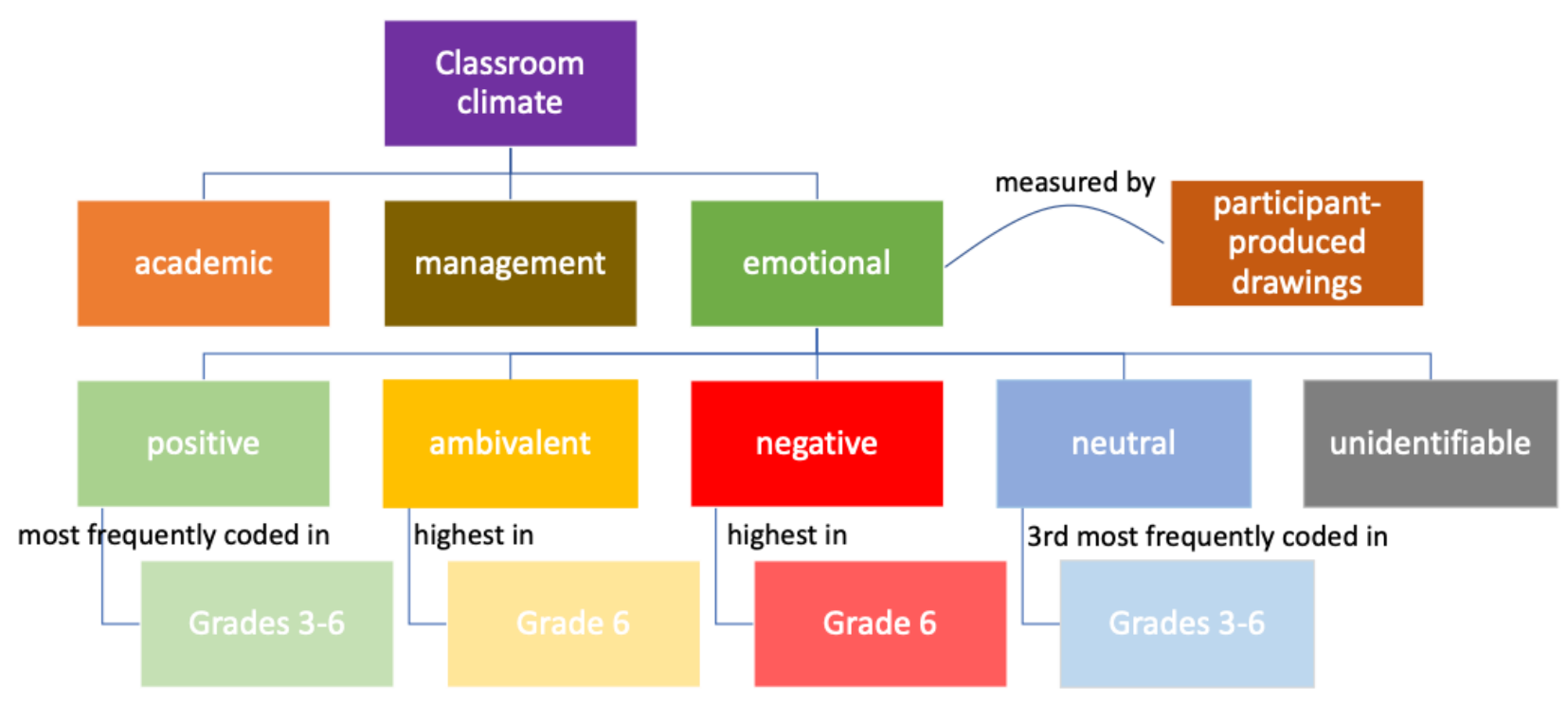


Over the course of their school years, many students experience both positive and negative emotions in various subjects (Reindl \& Hascher, 2013; vom Hofe et al., 2002). Among other things, emotions determine the behavior of those involved in teaching (Evans et al., 2009) as well as the willingness to learn and to perform, which are important components for school well-being (Schiepe-Tiska \& Schmidtner, 2012). Furthermore, a positive teacher-child relation advances both students' social accommodation and their orientation to school, and thus is an important foundation for their academic career in the future (Harrison et al., 2007). In recent decades, the study of emotions has gained greater prominence in educational research (Hascher \& Edlinger, 2009), often with a focus on specific emotions, such as the joy of learning (Schmude, 2005). The international comparative study PISA 2012 also analyzed, among other things, emotional orientation in mathematics (Schiepe-Tiska \& Schmidtner, 2012). In PISA 2012, Germany performed slightly below the OECD average in terms of the emotional orientation of enjoyment in mathematics (SchiepeTiska \& Schmidtner, 2012). Overall, only 39\% of 15-year-old students reported liking mathematics and engaging in mathematics because they enjoyed it (Schiepe-Tiska \& Schmidtner, 2012).

In mathematics education, the topic of emotions already has its field of research (e.g., Dahlgren Johansson \& Sumpter, 2010; Laine et al., 2013, 2015; Reindl \& Hascher, 2013; Tuohilampi et al., 2016; vom Hofe et al., 2002). For example, in the PALMA study ("Project for the Analysis of Learning and Achievement in Mathematics"), it has been confirmed that emotions have a strong influence on the mathematical competence growth of Grade 5-10 students (vom Hofe et al., 2002). Here, the joy of learning correlated positively with interest and motivation to learn, among other things, whereas anxiety and boredom were recognized as negative influencing factors (vom Hofe et al., 2002). Similarly, Frenzel and Stephens (2007) in their study with Grades 5-10 students reported on a close connection between the classroom climate and learning achievements as well as emotional and social experiences. These results make clear what significance both positive and negative emotions may have for mathematics development at primary school age.

Another area of research in the field of emotions focuses on the development of emotions over the school years. In a study by Reindl and Hascher (2013), a decrease in positive emotions was recorded in mathematics classes, which negatively affected attitudes toward mathematics as a subject. Hascher et al. (2011) also pointed out that 
positive emotions decrease over the elementary school years. Previous research on emotions focused mainly on mathematics education in general, but not specifically on different mathematical content, such as arithmetic (Reindl \& Hascher, 2013; Schmude, 2005), geometry (Glasnović Gracin \& Kuzle, 2018), or how these develop during the elementary school years. School geometry is a subject area of mathematics that is often disregarded and referred to as the "stepchild" of mathematics education (Backe-Neuwald, 2000; Eichler, 2005). However, geometry didactics (e.g., Krauthausen, 2018) especially emphasizes that geometry instruction may help students develop a positive attitude towards mathematics due to its motivating effect on students through alternative instructional concepts (e.g., action-oriented instruction, discovery learning) and a sense of achievement by experiencing success. This led to an increased interest in how elementary school children feel during this large laissez-faire subfield of mathematics lessons. More specifically, the main goal of the inquiry presented in this paper was to provide insight into the emotional classroom climate in primary grade geometry lessons ${ }^{1}$ and to find out if previously reported trends also apply to them. For this purpose, participant-produced drawings were used, which allow a constructive process of thinking in action, rather than seeing drawings as simple representations of the participant's worldviews (Kearney \& Hyle, 2004).

\section{Theoretical foundation}

In this section, I present the constructs of classroom climate and emotional classroom climate and place them in the context of this work (i.e., drawings as a research method). Emotional classroom climate research in mathematics using drawings is then presented. The section ends with the two research questions that guided the study.

\subsection{Emotional classroom climate}

The classroom is a significant environment in the development of children which with time develops a distinct climate or feel (Ashkanasy, 2003). It shapes students' essential perceptions, and it allows each child to acquire new concepts and

\footnotetext{
${ }^{1}$ In the federal states of Berlin and Brandenburg (Germany) where the study was conducted, primary education covers
} Grades 1 to 6 . 
procedures, which are supported by the teacher and the teacher's choice of activities (Ahtee et al., 2016). According to researchers (Evans et al., 2009; Hannula, 2012), the classroom climate refers to a shared subjective representation of important characteristics of the classroom which, however, differ in their climate-creating determinants. Götz et al. (2011) presented a general statement for the "emotional aspects" of climate. They refer to both positive and negative emotions of a group. In addition, "perceived affective attitudes" (Götz et al., 2011, p. 506) related to the school, people who are associated with the school, areas of specialization, and subjects taught are, among others, the emotional aspects of classroom climate. On the other hand, Evans et al. (2009) divided the notion of classroom climate into three complementary components: academic, referring to pedagogical and curricular elements of the learning environment; management, referring to discipline styles for maintaining order; and emotional, referring to affective interactions within the classroom. Furthermore, Evans et al. (2009) argued for the importance of treating emotional climate as a distinct aspect of classroom climate as it is "superordinate to other classroom climate domains since it interfaces with the conventional academic and management elements of effective learning environments" (p. 131). In this study, I concentrate on the last component, namely the emotional classroom climate, which can be described as an emotional relationship between the students and the teacher.

According to Hannula (2012), the emotional climate in the classroom can be regarded from a psychological and social point of view (see Table 1). The psychological dimension refers to the level of an individual and involves affective conditions (i.e., emotions and emotional reactions, thoughts, meanings, and goals), and affective properties (i.e., attitudes, beliefs, values, and motivational orientations). The social dimension refers to the classroom community. Its affective conditions refer to social interaction, communication, and the atmosphere in a classroom (momentarily), whereas affective properties refer to norms, social structures, and the atmosphere in the classroom. Here, the focus is on the former. 
Table 1. Dimensions of the emotional climate in a classroom

\begin{tabular}{lll}
\hline & $\begin{array}{l}\text { Psychological dimension or the } \\
\text { level of the individual }\end{array}$ & $\begin{array}{l}\text { Social dimension or the level of } \\
\text { the community (classroom) }\end{array}$ \\
\hline Affective condition (state) & $\begin{array}{l}\text { Emotions and emotional } \\
\text { reactions } \\
\text { Thoughts } \\
\text { Meanings }\end{array}$ & $\begin{array}{l}\text { Social interaction } \\
\text { Communication } \\
\text { Goals }\end{array}$ \\
& $\begin{array}{l}\text { Atmosphere in the classroom } \\
\text { (momentarily) }\end{array}$ \\
& $\begin{array}{l}\text { Attitudes } \\
\text { Beliefs } \\
\text { Values } \\
\text { Motivational orientations }\end{array}$ & $\begin{array}{l}\text { Norms } \\
\text { Social structures } \\
\text { Atmosphere in the classroom }\end{array}$ \\
\hline
\end{tabular}

In both dimensions, one can distinguish between two temporal aspects of affect, namely state and trait. State (affective condition) refers to the emotional atmosphere at a specific moment in the classroom, such as different emotions and emotional reactions (e.g., fear and joy), thoughts (e.g., "This is difficult."), meanings (e.g., "I could do it."), and aims (e.g., "I want to solve this task.") (Laine et al., 2013). They influence critical decisions and determine whether a problem is solved by an individual or not and change rapidly. Trait (affective property) refers to more stable conditions or properties, such as attitudes (e.g., "I like math."), beliefs (e.g., "Math is difficult."), values (e.g., "Math is important."), and motivational orientations (e.g., "I want to understand.") (Laine et al., 2013, 2015). They provide a consistent pattern of how an individual thinks or feels in a situation (Hannula, 2012). Both temporal aspects of affect can be applied to the context of the school. For instance, in situations of a similar nature that occur repeatedly in the classroom (i.e., checking of homework, discussion of assignments), students develop affective characteristics (traits) typical of that situation. Social norms, social structures, and the prevailing atmosphere in the classroom are described as such traits (Hannula 2012; Laine et al. 2013). Given the teacher's central role in constructing the emotional climate or being the emotional force in day-to-day school lessons (Evans et al., 2009), recurring situations may have an influence on students developing more stable affective traits typical to a certain classroom (Laine et al., 2013). 


\subsection{Drawings as a research method}

In recent decades childhood research has experienced a paradigm shift that has had a comprehensive impact on research design and methods. While it was common to view children as objects, the shift has led to children being increasingly viewed as subjects in the research process by using methodologies such as observations or test procedures (Hill, 1997). Among other things, this shift has led to increased use of participatory and visual methods and processes in childhood research. With respect to visual research, drawings, videos, and photographs have been recognized as one of the crucial methods (Einarsdóttir, 2007). Visual methods are not only effective because of the richness of produced data, but also because of the quality of the data providing insights into children's everyday lives (Einarsdóttir, 2007). Drawing is a creative method based on inventive and imaginative processes with drawings as a research tool having the function of capturing children's individual experiences (Veale, 2005). Children perceive drawing as a way of expressing themselves (Laine et al., 2015). Their drawings are shaped by "perception, emotions and motivations, cognitions, and skills and abilities" (Gramel, 2008, p. 34). Guided by emotion, children communicate through drawings what occupies them, what is important to them, and what they experience (Gramel, 2008), and thus provide a holistic insight into their emotional lifeworld (Einarsdóttir, 2007; Kearney \& Hyle, 2004; Veale, 2005). For children, drawing is much more than a simple representation of what they see before them; rather it can be understood as one way in which they are making sense of their experiences (Anning \& Ring, 2004).

Drawings are considered a useful research method when subjects cannot adequately express or verbalize content in response to research questions, as they require little or no language mediation (Thomson, 2008; Weber \& Mitchell, 1996). Another advantage of using drawings as a research object is that the interviewees, through the support of the drawings, answer honestly and reduce their answers to the essentials (Nossiter \& Biberman, 1990). Moreover, children participate more in research when it is fun for them and when they can express their creativity (Punch, 2002). Through colors, in particular, children can highlight emotions and create an effect in the viewer and the drawer themselves (Neuß, 2014). According to Harrison et al. (2007), emotions that are felt particularly negatively can be better expressed in drawings than through language. Furthermore, the drawers can be observed while drawing (Clark, 2005; Einarsdóttir, 2007; Punch, 2002), and thus the interpretations of the drawers themselves, or explanations about the drawn image can be 
experienced. Additionally, Kearney and Hyle (2004) found that using participantproduced drawings is more likely to accurately represent participants' experiences and emotions. Participant-produced drawings function as a catalyst, helping participants to articulate their feelings, emotions, and lived experiences. In that manner, the participant approach allows for depth of discussion, participant's shaping of agenda, and encourages collaborative meaning-making as well as reliable and trustworthy data (Kearney \& Hyle, 2004).

\subsection{Emotional classroom climate research}

Current research on emotions and their development in mathematics education focused mainly on the secondary and less on the primary level (Reindl \& Hascher, 2013). Yet, research across disciplines shows there is a decline in enthusiasm for learning and school over the first years of education, and everyday school life is increasingly accompanied by negative emotions (e.g., Helmke, 1993; Reindl \& Hascher, 2013). Here, especially negatively experienced emotions, such as boredom, are the main accompanying symptoms of school experience (Eder, 1995). For instance, Reindl and Hascher (2013) investigated the emotional feelings (i.e., joy, interest, anger, fear, and boredom) of 165 Austrian elementary school students ${ }^{2}$ in Grades 1 to 4 during mathematics lessons using a questionnaire at different points in time over a period of two school years. In particular, they were interested in whether a decrease in the positively experienced emotions of joy and interest had an effect on the negatively experienced anger, fear, and boredom. They reported that positive emotions were more pronounced than negative emotions in each of the grade levels studied, with Grade 1 students showing the most positive emotions, meaning that "children [...] experience more positive and fewer negative emotions toward mathematics" (Reindl \& Hascher, 2013, p. 283) at the beginning of their schooling. Over the course of the first school year, the positive emotions decreased. In the survey, positive emotions increased in Grade 2 and remained relatively stable in Grades 3 and 4 (Reindl \& Hascher, 2013). Specifically, the students experienced overall the emotion of joy at a relatively high level. Within the respective school years, a decrease in negatively experienced emotions was always ascertainable (Reindl \& Hascher, 2013). Although negative emotions are subject to a slight recovery effect during the transition from primary to secondary school (van Ophuysen, 2008), a stronger focus on primary

\footnotetext{
${ }^{2}$ The sample was reduced to 121 students in the course of the study.
} 
grades is important and necessary.

Although numerous studies researching emotions employed methods such as interviews, observations, and questionnaires (e.g., Reindl \& Hascher, 2013; Schmude, 2005), in the last decade, there has been an increase in studies on emotions and emotional classroom climate using visual research methods, such as drawings (e.g., Dahlgren Johansson \& Sumpter, 2010; Glasnović Gracin \& Kuzle, 2018; Laine et al., 2013, 2015, 2020; Tuohilampi et al., 2016). These studies have shown that children's drawings have great potential to provide a thorough insight into different aspects of classroom climate in school mathematics. For instance, Laine et al. (2013) investigated the emotional atmosphere of 133 Finnish Grade 3 students from a total of nine mathematics classes, using students' drawings only. The emotional classroom climate was classified into five categories (i.e., positive, ambivalent, negative, neutral, unidentifiable) based on the students' and teachers' mode (i.e., facial expressions) as well as on their speech and thought bubbles illustrated in the drawings. Overall, $38 \%$ of the drawings showed a positive emotional atmosphere in mathematics class. In addition, $33 \%$ of the drawings were rated as ambivalent, $15 \%$ as neutral, $5 \%$ as unidentifiable, and 10\% with a negative emotional atmosphere (Laine et al., 2013). Since the difference between positive and ambivalent categories was not that big, Laine et al. (2013) concluded that the emotional atmosphere in Grade 3 mathematics classes was mainly positive. In a further study, Laine et al. (2015) researched the emotional atmosphere of 136 Finnish Grade 5 students from a total of eight mathematics classes. The research design and the evaluation of the children's drawings followed the same criteria as in the study of third graders (Laine et al., 2013). Overall, $36 \%$ of the drawings showed a positive classroom climate, $34 \%$ ambivalent, $13 \%$ neutral, $14 \%$ negative, and $3 \%$ were not identifiable. Since both reported studies (Laine et al., 2013, 2015) addressed the same research questions, a comparison of the results between Grade 3 and Grade 5 students is possible. Over the course of the school years, the proportions of atmospheres drawn that were rated as positive as well as those rated as negative changed between the two grade levels. The assessment of drawings depicting negative emotional atmospheres in mathematics lessons noticeably increased. There was an increase of $4 \%$ compared to the third graders from the study two years earlier. In total, $14 \%$ of the drawings were assessed as negative, whereas the percentage of positively rated drawings (38\%) decreased by $2 \%$ to $36 \%$ (Laine et al., 2015). Thus, the results of both studies suggested there was a negative 
trend regarding emotional atmosphere in mathematics classrooms over the school years (Laine et al., 2020).

Similarly, Dahlgren Johansson and Sumpter (2010) presented a comparative analysis of children's conceptions of mathematics and mathematics education in Grades $2(\mathrm{~N}=19)$ and $5(\mathrm{~N}=11)$ using drawings. The results showed that there was a significant decrease in positively perceived attitudes toward the subject of mathematics from the study group of Grade 2 to the study group of Grade 5 students. Overall, only five Grade 5 students rated their attitude toward mathematics as positive, in contrast to 17 positive ratings from Grade 2 students. The most frequently displayed emotion of Grade 2 students was happiness, sometimes combined with a quirky thoughtfulness, whereas Grade 5 students most frequently displayed calmness and frustration (Dahlgren Johansson \& Sumpter, 2010).

In comparison to the above-mentioned studies, Glasnović Gracin and Kuzle (2018) analyzed the emotional climate in school mathematics in the context of geometry lessons using participant-produced drawings. Here, a multiple case study with four high-achieving Croatian students from Grades 2 to 5 was conducted. The drawings were analyzed based on facial features, and thought and speech bubbles as suggested by Laine et al. (2013, 2015), and Zambo (2006), but expanded by also looking at body language. The results of the study were aligned with those of Laine et al. (2013) with the emotional climate in geometry lessons on the level of the individual being positive (Grades 2-3), unidentifiable (Grade 5) or ambivalent (Grade 4), but in no case dominantly negative. Since a multiple case study was conducted, Glasnović Gracin and Kuzle (2018) could not portray a comprehensive picture of the emotional climate in geometry lessons, but rather case-based results. For that reason, the results were neither representative of a broader population nor generalizable.

\subsection{Research questions}

In this study, I aim to contribute to the research of the mathematics-related affect by presenting a detailed inventory to determine the emotional classroom climate in geometry lessons using participant-produced drawings, by providing insight into the emotional classroom climate in primary grade geometry lessons, and by examining the grade level's effect on that. The exact research questions are:

1. What kind of emotional classroom climate in geometry lessons can be seen in primary Grade 3-6 participant-produced drawings? 
2. What similarities and differences in participant-produced drawings exist among elementary Grades 3-6 from the perspective of the emotional classroom climate in geometry lessons?

\section{Research process}

\subsection{Research design and subjects}

For this study, an explorative cross-sectional qualitative research design (Patton, 2002) using participant-produced drawings (Kearney \& Hyle, 2004) was chosen. The study participants were 114 elementary school students (Grades 3 to 6). This age group was optimal as they had already gathered enough experience in school mathematics. Furthermore, according to Lucquet's developmental-stage theory (1913, 1923, in Anning \& Ring, 2004), the children are either at a schematic stage (ages 7 to 9 years) or visually unrealistic stage (ages 9 to 11 years) of drawing. Thus, the quality of drawings is already solid to high enough to allow rich insights into the emotional classroom climate. The distribution of students was as follows: 25 students from Grade 3, 33 students from Grade 4, 28 students from Grade 5, and 28 students from Grade 6. In the study, multiple urban schools from two federal states in Germany (i.e., Berlin and Brandenburg) participated in the project. Here, elementary schools were approached that fit the profile (i.e., not high- or low-ranked schools, but average urban schools). From the schools that agreed to participate, classes were selected that had at least one geometry lesson per week and, according to the teachers, may reflect the variety of emotional states in geometry instruction. From the same school, a maximum of two average students were randomly selected. Typical case sampling as a type of purposive sampling was utilized as a way of collecting rich and in-depth data and to allow for a comparison between other similar samples (Patton, 2002).

\subsection{Data collection instruments and procedure}

The main source of data was student work, namely student drawings, and a semistructured interview. Student work was based on an adaptation of the instrument from the work of Ahtee et al. (2016), and Laine et al. (2013, 2015). The research data were collected in a one-to-one setting between a student and the author of the paper. For the drawing, the students received instructions in the form of an Anna letter (Dohrmann \& Kuzle, 2014). Each student was given a piece of A4-paper with an 
assignment given by a fictional bright 12-year old girl by the name of Anna: "Dear , I am Anna and new to your class. I would like to get to know your class better. Draw two pictures of your mathematics lessons. The first drawing should show what your arithmetic lessons are like and how you view them. The second drawing should show what your geometry lessons are like and how you view them. In each drawing, include your teaching group, the teacher, and the pupils. Use speech bubbles and thought bubbles to describe conversation and thoughts. Mark the pupil that represents you in the drawing by writing "ME". Thank you and see you soon! Yours Anna." Here, only the second drawing is of relevance. After the students had finished drawing, the drawings were used as a catalyst for a semi-structured interview, as suggested by Kearney and Hyle (2004). During the interview, both a free description of the drawing on the part of the child were given (e.g., "Describe your picture to me.") and specific questions based on the child's description were posed (e.g., "How does the child 1, 2, etc. feel in the second drawing?", "What is the reason for that?").

\subsection{Data analysis}

The analysis of drawings was based on the holistic evaluation of the emotional classroom climate as suggested by Laine et al. (2013, 2015). Here each drawing was analyzed one content category at a time. Specifically, the evaluation was based on both the students' and the teacher's moods as well as on their speech and thought bubbles illustrated in the drawings. According to Koike (1997, cited in Gramel, 2008, p. 36) feelings can be divided into five categories of expression in drawings, namely facial expression, gestures, the facial schema, the representation of situations triggering emotions, and symbols. In the study, different facial features, and speech and thought bubbles were analyzed based on the coding manual developed by Zambo (2006), which was expanded with physical body features (i.e., body posture, arm position) as suggested by Glasnović Gracin and Kuzle (2018), to achieve a more accurate representation (see Table 2). 
Table 2. An excerpt from the coding manual

\begin{tabular}{|c|c|c|}
\hline Feature and thoughts & Nature and ranking & Clues \\
\hline \multicolumn{3}{|l|}{ Physical facial features } \\
\hline eyes & positive $(+1)$ & wide open \\
\hline mouth & neutral (0) & drawn as a straight line \\
\hline symbols drawn on face & negative $(-1)$ & $\begin{array}{l}\text { tears, tongue stuck out, teeth in } \\
\text { a growl }\end{array}$ \\
\hline \multicolumn{3}{|l|}{ Physical body features } \\
\hline arms & positive $(+1)$ & arms in the air, open arms \\
\hline arms & neutral $(0)$ & arms on the table \\
\hline arms & negative $(-1)$ & crossed arms \\
\hline \multicolumn{3}{|l|}{ Thoughts } \\
\hline symbols, signs, words, emotional words & positive $(+1)$ & $\begin{array}{l}\text { hearts, peace signs, thumbs up, } \\
\text { "easy", "fun", "I like” }\end{array}$ \\
\hline symbols, signs, words & neutral (0) & no expression \\
\hline symbols, signs, words, emotional words & negative $(-1)$ & $\begin{array}{l}\text { dark scribbles, sad, "blah, blah", } \\
\text { "hate", "too hard" }\end{array}$ \\
\hline
\end{tabular}

Concretely, in each drawing, both the depicted students as well as the teacher were examined according to the developed inventory. The analysis of the latter was necessary because the teacher influences the affective climate of the class (e.g., Harrison et al., 2007). I use Figure 1 for the purpose of explaining the coding process. The drawing does not represent a prototypical drawing, but rather has been selected on the basis of the scan quality. As shown in Tables 2 and 3, if a child's rating of a category was emotionally positive, a counter $(+1)$ was noted. If the assessment was negative, a negative counter $(-1)$ was noted, and if the assessment was neutral, the symbol o was noted (Zambo, 2006). If none of the categories was drawn, it was classified as unidentifiable and received a dash (-). After rating each feature, the "counters" were balanced against each other. If the score was o, the emotional state of the respective child was rated as neutral; if the score was positive, it was rated as positive; and if the score was negative, it was rated as negative. If an individual contained both positive and negative characteristics, it was coded as ambivalent. Thus, Kevin, depicted in Figure 1, was assigned + 2 counters, his emotional feeling was coded as positive. The same procedure was then used for all the other protagonists in the drawing (i.e., Jessica, Lucas, Leonie, the teacher). 


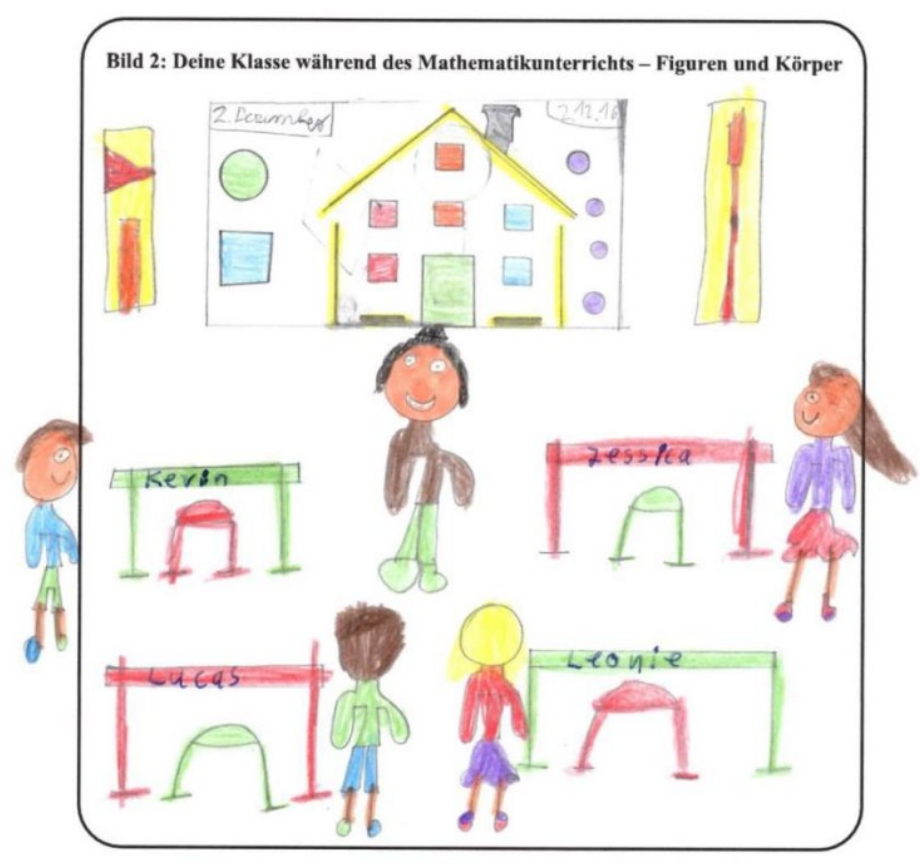

Figure 1. Exemplary coding of the emotional feeling of the drawn children

Following the rating of the children drawn, the holistic evaluation of the emotional climate in a geometry lesson was assessed. This was based on five categories reported in Laine et al. (2013, 2015) which was slightly adapted. These include the following emotional classroom climate categories: positive (i.e., the majority of persons smile, or think or behave positively, although some of the expressions can be neutral), ambivalent (i.e., there are both positive and negative facial/body language expressions or thoughts), negative (i.e., the majority of persons are sad or angry or think/behave negatively, although some of the expressions can be neutral), neutral (i.e., all facial/body language expressions or other thoughts are neutral, although some of the expressions can be either positive or negative), and unidentifiable (i.e., no facial/body language expressions or thoughts). If identifiable and non-identifiable persons were illustrated, only the non-identifiable ones were identified in the overall image analysis but were scored as neutral. To facilitate the interpretation of the children's drawings, the semi-structured interviews were transcribed. Multiple data sources (i.e., data triangulation) were used to assess the consistency of the results, and to increase the validity of the results (Kuzle \& Glasnović Gracin, 2020; Patton, 2002). Furthermore, they gave precise indications of the two temporal aspects of affect (i.e., state, trait). Going back to Figure 1, the interview confirmed that Kevin was in a positive mood and that he enjoyed geometry lessons very much. In addition, it provided information about the emotional state of two students, namely Lucas and 
Leonie, who were drawn from the back. In the drawing, only arm posture is visible (i.e., arms open downward) which would imply neutral counters in each case, and hence neutral emotional feeling. The interview, however, revealed that both Lucas and Leonie disliked geometry lessons, were not happy, and for that reason the drawer did not want to draw their faces. In this case, the interview added new information - or even gave a completely different picture of the emotional state of both children than one would take from the drawing itself. Thus, both children did not reflect a neutral emotional state but rather a negative one.

Table 3. Exemplary coding of the emotional feeling of the drawn child

\begin{tabular}{|c|c|c|c|c|}
\hline Child & $\begin{array}{l}\text { Physical and } \\
\text { speech/thought } \\
\text { bubble features }\end{array}$ & Feature clues & Explanation & Score \\
\hline \multirow[t]{9}{*}{ Kevin } & Facial features & mouth & smiling & +1 \\
\hline & & eyes/eyebrows & wide open & +1 \\
\hline & & face drawn symbols & - & - \\
\hline & \multicolumn{2}{|c|}{ Total: Physical face features } & & +2 \\
\hline & Body features & arm position & downward & 0 \\
\hline & Speech/thought & symbols & - & - \\
\hline & bubble features & signs & - & - \\
\hline & & words & - & - \\
\hline & \multicolumn{3}{|c|}{ Total: Speech/thought bubble features } & - \\
\hline Total: Kevin & & & & +2 \\
\hline
\end{tabular}

The two researchers coded the students' data separately from one another. The interrater reliability was high (90\% agreement). Nevertheless, we discussed the differences in coding taking into consideration both students' products, and refined the coding manual. It was agreed that the final decision about the nature of a counter assigned to a particular physical feature would be based on the interview data, as was exemplarily elaborated earlier when describing the process of data analysis. This decision mainly related to the drawings in which the protagonists were depicted from behind or in an extremely simplified or generic manner. Furthermore, there were a few disagreements regarding the nature of individual thought features, such as "good", "okay" which were then discussed. Adjustments were subsequently made to our coding, after which the interrater reliability was $100 \%$. 


\section{Results}

This section is divided into two parts. The first part focuses on the emotional classroom climate in Grades 3-6 geometry lessons. The second part focuses on the differences and similarities in the emotional classroom climate across four grade levels.

\subsection{Emotional classroom climate in geometry lessons through the lens of Grades 3-6 participant-produced drawings}

After analyzing the physical features (i.e., face and body), and the speech and thought bubbles of the children and the teacher depicted in the drawings, they were classified into five categories (i.e., positive, negative, ambivalent, neutral, unidentifiable). In Table 4 the results regarding the emotional classroom climate in Grades 3-6 geometry lessons are presented.

Table 4. Emotional classroom climate in primary grade geometry: absolute and relative frequencies

\begin{tabular}{lllllll}
\hline \multicolumn{7}{c}{ Emotional classroom climate categories } \\
\hline Grade & $\mathrm{N}$ & positive & ambivalent & negative & neutral & unidentifiable \\
3 & 25 & $15(60 \%)$ & $6(24 \%)$ & $1(4 \%)$ & $2(8 \%)$ & $1(4 \%)$ \\
4 & 33 & $14(42 \%)$ & $9(27 \%)$ & $3(9 \%)$ & $5(15 \%)$ & $2(6 \%)$ \\
5 & 28 & $13(46 \%)$ & $10(36 \%)$ & $2(7 \%)$ & $2(7 \%)$ & $1(4 \%)$ \\
6 & 28 & $13(46 \%)$ & $12(43 \%)$ & $0(0 \%)$ & $2(7 \%)$ & $1(4 \%)$ \\
Total & 114 & $55(48 \%)$ & $37(33 \%)$ & $6(5 \%)$ & $11(10 \%)$ & $5(4 \%)$ \\
\hline
\end{tabular}

4.1.1: Emotional classroom climate in Grade 3. In total, 15 drawings (6o\%) by Grade 3 students represented the emotional climate in the geometry classroom as positive. The drawing shown in Figure 2 is an example of a drawing that was rated as positive, as both the children and the teacher are smiling. The eyes of all three protagonists are typical with no expression (i.e., round eyes), which were coded as neutral. The arm posture of child 1 is neutral (i.e., arms closed next to the body holding two objects), whereas that of child 2 and of the teacher is positive as their arms are open upwards. The arm posture of child 2 signalizes that she raised her hand to answer the teacher's question, and in that manner is engaging in conversation, though the drawer did not have any speech bubbles. The interview revealed that this drawing illustrates an everyday teaching situation in geometry lessons. The teacher is often in a good mood and the students like geometry. Thus, these are permanently valid characteristics of 
geometry lessons (trait). The positive emotional climate was in almost all cases described as a trait.

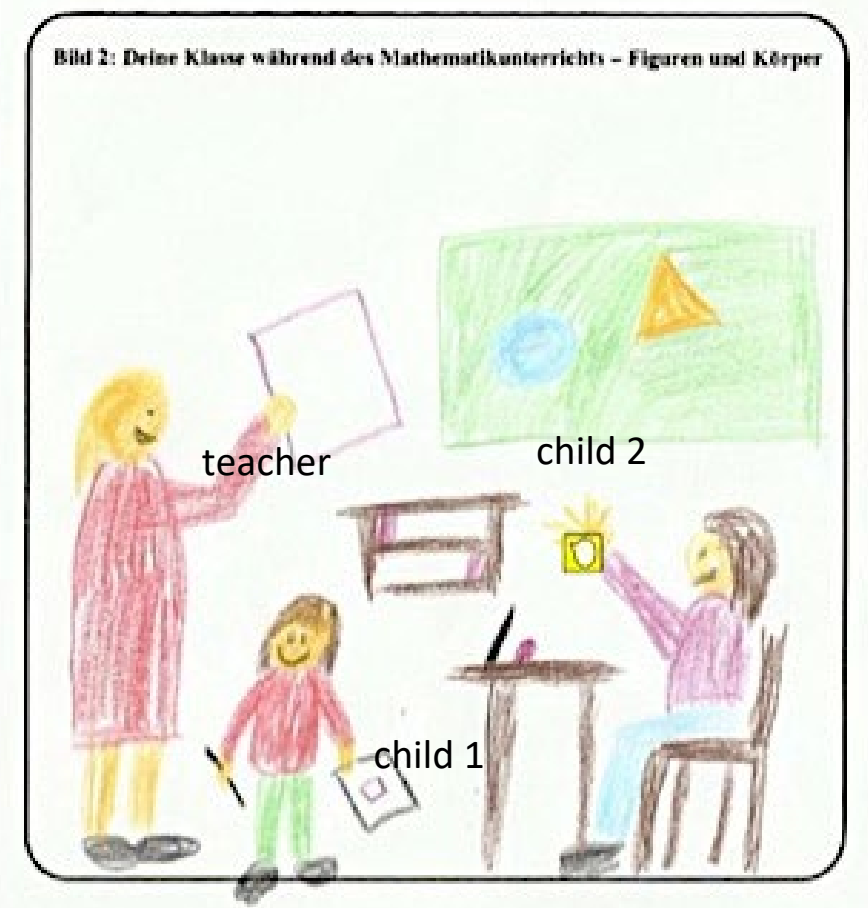

Figure 2. A Grade 3 student's drawing of a positive emotional classroom climate.

In total, six drawings (24\%) by Grade 3 students represented the emotional climate in the geometry classroom as ambivalent since both positive (e.g., protagonists smiling, arms open upwards, "I am in a good mood.", "I like geometry."), as well as negative features (e.g., mouth turned downward, closed eyebrows, mouth open in a scream, "I find geometry hard.", "boring”), were illustrated. The interviews revealed that in half of the drawings this was a permanent characteristic of geometry lessons (trait), whereas in the rest of the drawings it was a temporal characteristic of geometry lessons (state). Only one Grade 3 student (4\% of drawings) represented the emotional climate in the geometry classroom as negative with almost only negative features (e.g., mouth turned downward, tears on the face, eyebrows slanted inward and contracted, tears, mouth open in a scream, “!”) and some neutral ones (e.g., arms closed downwards, eyes typical with no expression) were illustrated. However, the drawer elaborated in the interview that the mood was determined by a quarrel between the students, and that this situation did not reflect a permanent condition in geometry lessons, but a condition of the emotional classroom climate at a specific moment (state). 
In total, two Grade 3 students (8\% of drawings) represented the emotional climate in the geometry classroom as neutral. This can be recognized by neutral body language (e.g., hands placed on the desks) and neutral thought and speech bubbles (e.g., "Open your books at pages 16-17. We are doing these pages now.", "OK."). Whereas the interview revealed that the first drawing represented a stable condition (trait), the second drawing represented a specific moment in the geometry class (state). Only one Grade 3 student's drawing was rated as unidentifiable. In this drawing, there were no facial or body expressions, and speech and thought bubbles could not be identified. Children's names are written on drawn rectangles, which most likely represented desks. Likewise, the interview did not provide any further information.

To summarize, in the sample of Grade 3 students' participant-produced drawings, the emotional classroom climate in geometry was predominantly (more than half) positive and a rather stable condition (trait). Only one drawing showed a completely negative emotional classroom climate which, however, reflected a temporary situation of geometry teaching (state). The few cases of ambivalent classroom climate had more positive emotional features than negative ones.

4.1.2: Emotional classroom climate in Grade 4. In total, 14 drawings (42\%) by Grade 4 students represented the emotional climate in the geometry classroom as positive, depicting only positive features (e.g., full smile, arms open upwards, wide-open eyes, “That is easy.") with occasionally also neutral ones (e.g., eyes with no expression, mouth drawn as a straight line, a mathematical expression such as "a circle") were illustrated. Furthermore, nine drawings (27\%) by Grade 4 students represented the emotional climate in the geometry classroom as ambivalent since both positive (e.g., protagonists smiling, wide open eyes, arms open upwards, "I like it.", "I can do geometry."), as well as negative features (e.g., mouth turned downward, tears on the face, eyes in a downward slant, "boring”, "oh no, not today", "zzz"), were illustrated. Only three students ( $9 \%$ of drawings) represented the emotional climate in the geometry classroom as negative since only negative features (e.g., mouth turned downward, eyebrows slanted inward, "not again", "Finally, we get to go home.") with some neutral ones (e.g., arms closed downwards) were illustrated. The drawing shown in Figure 3 is an example of a drawing that was rated as negative. The arm posture of all three protagonists is neutral (i.e., arms in action). The eyes of child 2 are typical with no expression (i.e., round eyes) which were coded as neutral. However, a speech bubble contains the word "aua" which reveals a negative state of mind (i.e., "uoch"). The teacher's thought bubble "Finally home." also reflects a negative condition. The 
interview revealed that the drawer provided an illustration of an everyday situation: some children are bored and his math teacher is happy that it is the end of the lesson. Thus, these are permanently valid characteristics of geometry lessons (trait).

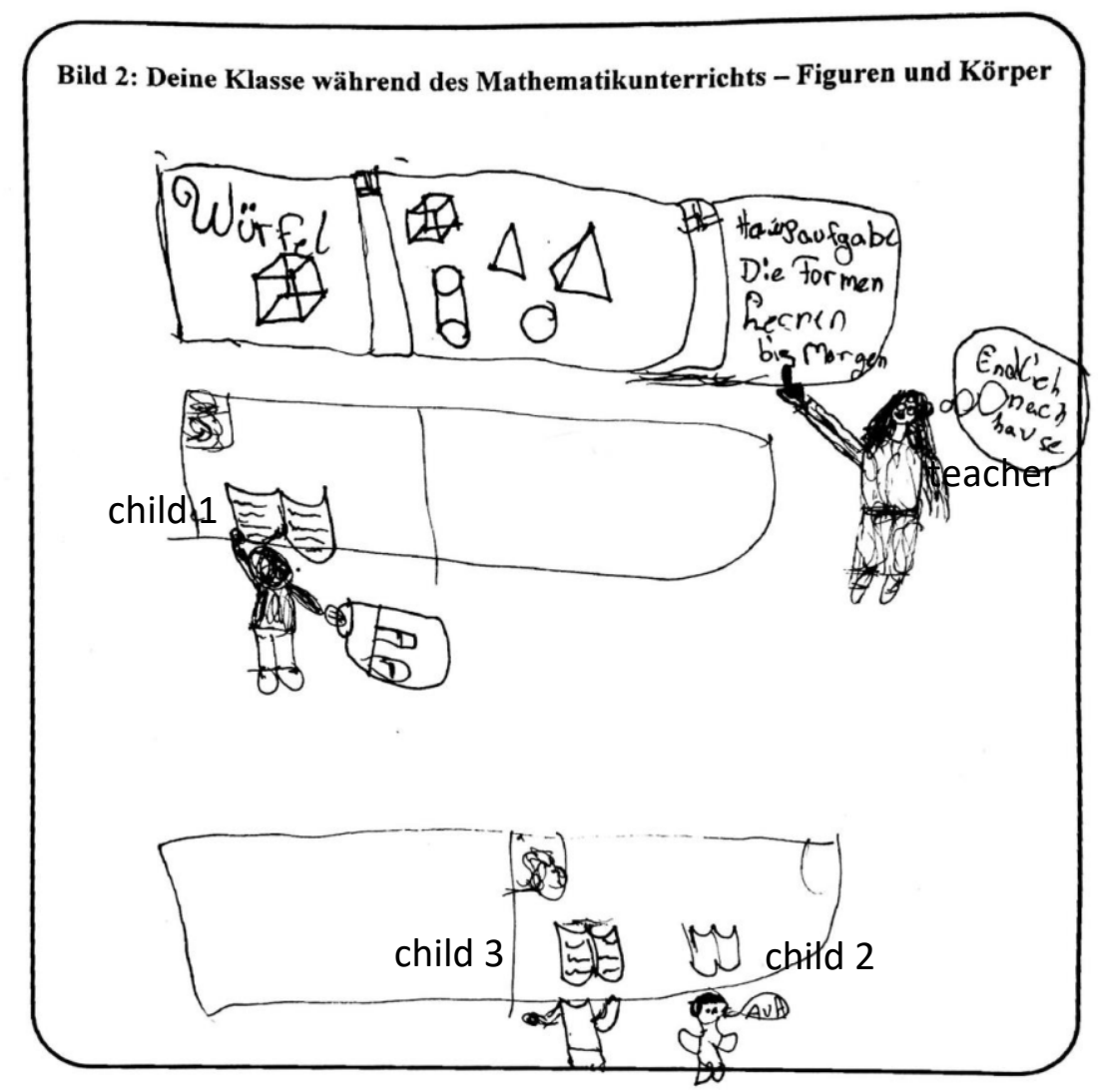

Figure 3. A Grade 4 student's drawing of a negative emotional classroom climate.

In total, five Grade 4 students (15\% of drawings) represented the emotional climate in the geometry classroom as neutral since only neutral features were illustrated or mentioned (e.g., hands on the table, eyes with no expression, mouth drawn as a straight line, mathematical statements such as "A circle."). Two drawings were rated as unidentifiable (6\% of drawings). In these drawings, there were no facial or body expressions, and speech and thought bubbles could not be identified. Likewise, the interview did not provide any further information.

To summarize, in the sample of Grade 4 students' participant-produced drawings, the drawings portraying a positive classroom climate had the highest frequency, but they did not predominate. However, in all but one drawing a positive emotional climate was a stable condition (trait). Only three drawings showed a completely negative emotional classroom climate which, on the downside, reflected a permanent 
condition (trait). The cases of drawings reflecting an ambivalent classroom climate were dominated by positive emotional features with a few negative ones.

4.1.3: Emotional classroom climate in Grade 5. Almost half of the drawings (46\%, $\mathrm{n}=13$ ) by Grade 5 students represented the emotional climate in the geometry classroom as positive since often only positive features (e.g., full smile, arms open upwards, wide open eyes) with occasionally also neutral ones (e.g., eyes with no expression) were depicted. The interviews revealed that in all cases but two, the drawings represented a stable condition in the geometry lesson (state). More than one-third of the drawings $(36 \%, \mathrm{n}=10)$ were rated as ambivalent with both positive (e.g., arms open upwards, full smile, "I understand it.") and negative features (e.g., mouth turned downward, "boring", "wake up") being illustrated or mentioned. In three cases, the drawings reflected a temporary emotional condition (state), whereas in six cases a stable condition (trait). No drawing contained more than one negative expression. Furthermore, two drawings ( $7 \%$ of drawings) represented the emotional climate in the geometry classroom as negative since only negative features (e.g., "shut up", "zzz") with some neutral ones (e.g., arms closed downwards) were illustrated, which, however, reflected a temporary condition (state). In total, two Grade 5 students (7\% of drawings) represented the emotional climate in the geometry classroom as neutral since only neutral features were illustrated or mentioned (e.g., hands on the table, eyes with no expression, mouth drawn as a straight line, mathematical statements such as "I'm drawing a prism."). Only one drawing was rated as unidentifiable (4\% of drawings). In this drawing, there were no facial or body expressions, and speech and thought bubbles could not be identified. Likewise, the interview did not provide any further information.

To summarize, in the sample of Grade 5 students' participant-produced drawings, a positive classroom climate was portrayed most frequently, but did not predominate. In most of these drawings, a positive emotional climate was a stable condition (trait). The percentage of drawings illustrating an ambivalent classroom climate was slightly lower than those illustrating a positive classroom climate. Also, these drawings predominantly reflected a stable condition (trait). Only a few drawings illustrated a negative or a neutral emotional classroom climate. The former, however, reflected a temporary condition (state). 
4.1.4: Emotional classroom climate in Grade 6. Almost half of the drawings (46\%, $\mathrm{n}=13$ ) of Grade 6 students represented the emotional climate in the geometry classroom as positive since often only positive features (e.g., smile, arms open upwards, engaging arms, wide open eyes, eyebrow upward slant, smiley) with occasionally also neutral ones (round eyes with no expression, "A triangle.") were depicted. The interviews revealed that in all cases the drawings represented a stable condition (state). Furthermore, 12 drawings (43\%) by Grade 6 students represented the emotional climate in the geometry classroom as ambivalent since both positive (e.g., protagonists smiling, arms are open upwards, "That's easy!", raising arm), as well as negative features (e.g., mouth turned downward, closed eyes, "Oh no!”, “zzz”), were illustrated. The interviews revealed that in all cases but one, the drawings represented a stable condition (trait). The drawing shown in Figure 4 is an example of a drawing that was rated as ambivalent.

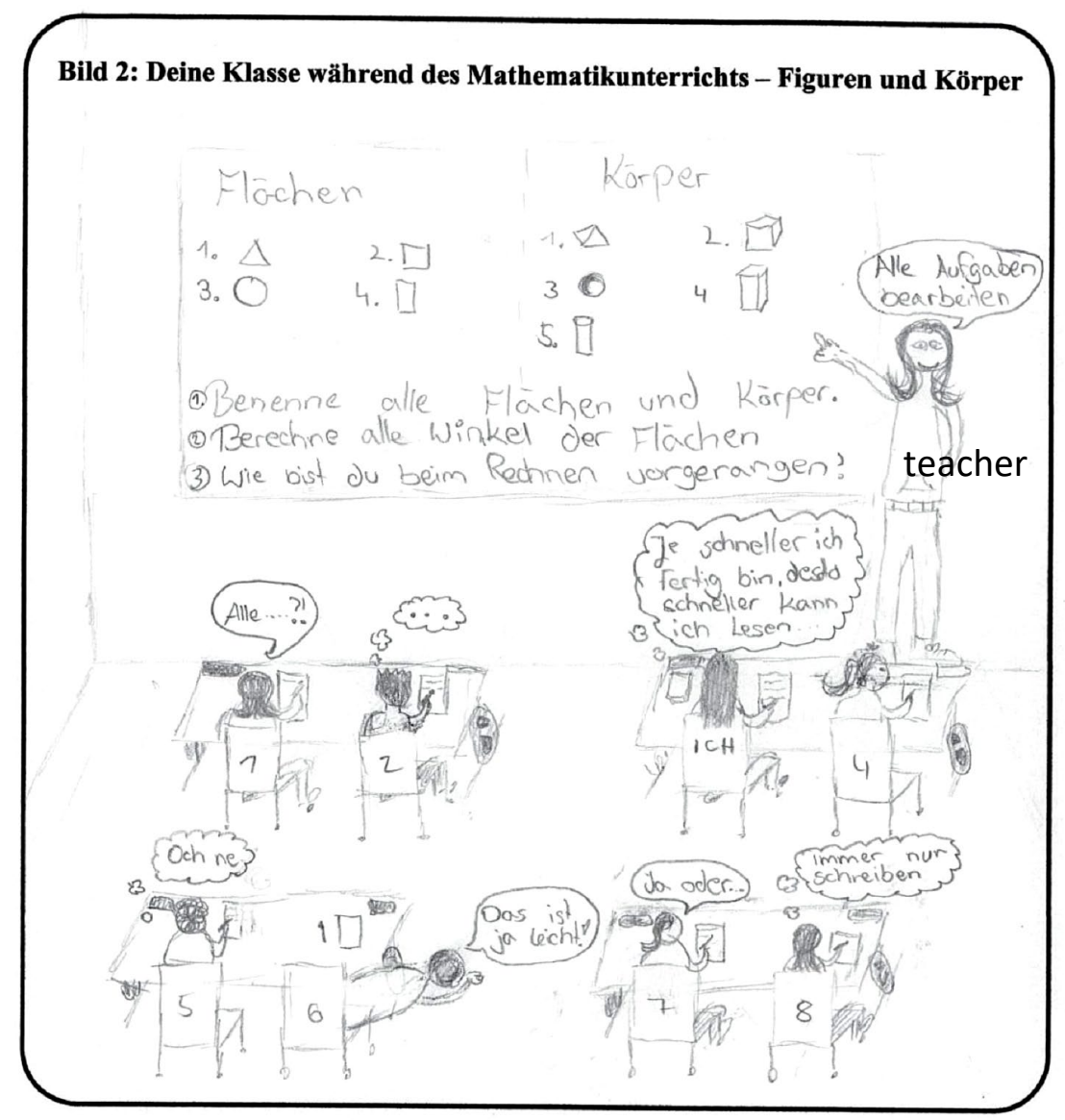

Figure 4. A Grade 6 student's drawing of an ambivalent emotional classroom climate.

Specifically, the teacher is depicted as smiling (i.e., positive emotional state). Her arms are in motion as she is pointing at the board and assigning the students the 
following task "Do all the tasks." (i.e., neutral feature). In total, eight children are illustrated in the drawing. Two children, namely child 4 and child 6 embody positive emotions since child 4 is smiling, and the arms of child 6 are open upwards with a speech bubble "That is easy". Two children, namely child 2 and child 7 reflect a neutral emotional state since only two neutral statements are illustrated in the thought bubble (i.e., “...”, "yes or...”). Lastly, four children elicit negative features regarding the emotional classroom climate. Child 1 is illustrated with a speech bubble "All ... [of them]?!", child 3 ("Ich = me") with a though bubble "The faster I finish, the faster I can read.", child 5 with a thought bubble "Oh no.", and child 8 with a thought bubble "Always just writing.". All of these reflect dissatisfaction with the classroom activities, and in that manner express negative emotions towards the geometry lesson. The interview revealed that even though the drawing illustrated a particular geometry lesson, that this reflected geometry lessons in general, and hence a permanent condition (trait).

No drawing from Grade 6 students depicted a negative classroom climate. Two drawings only (7\%) represented a stable neutral emotional classroom climate in geometry lessons, which contained protagonists with neutral body language (e.g., hands on the table), as well as neutral thought and speech bubbles ("A circle.", "A cube has 6 faces.”). There was no evidence of positive or negative emotions. Lastly, one drawing was rated as non-identifiable since it did not show any form of emotional representation.

To summarize, in the sample of Grade 6 students' participant-produced drawings, a positive classroom climate was portrayed with the highest frequency, but it did not predominate. In all cases, a positive classroom climate was a stable condition (trait). The percentage of drawings illustrating an ambivalent classroom climate was very similar to those illustrating a positive classroom climate. These drawings also reflected a rather stable condition (trait). None of the drawings reflected a negative emotional classroom climate.

\subsection{Emotional classroom climate in primary geometry education through students' lenses: Similarities and differences}

Here, the focus was to evaluate the distribution of emotional classroom climate categories. Given the cross-sectional design, it is not possible to show a progression of the emotional classroom climate over the school period. For that reason, the results are discussed with respect to the similarities and differences of the distribution 
regarding the different grade levels.

As shown in Table 4, a positive classroom climate was most frequently coded (48\% of drawings). This was independent of the grade level, where almost all the students' drawings included at least one positive emotional feature. This was followed by ambivalent, neutral, and negative emotional classroom climates, with 33\%, 10\%, and $5 \%$ of drawings, respectively. In total, only $4 \%$ of drawings were rated as unidentifiable. With respect to the positive classroom climate a decrease from the lower (6o\% in Grade 3) to the higher grades is observable (46\% in Grades 5 and 6), reaching its minimum in Grade 4 (42\%). In other words, drawings portraying a positive classroom climate in geometry lessons were only dominant in Grade 3 (i.e., more than $50 \%$ of drawings). However, independent of the grade level almost all the drawings reflected a positive emotional classroom climate as a stable condition (trait). With respect to the ambivalent classroom climate, an increase from the lower $24 \%$ in Grade 3) to the higher grades is observable (43\% in Grade 6), which - independent of the grade level - reflected in almost all drawings a stable condition. Thus, Grade 6 students more often drew negative facial expressions, body postures, thought or speech bubbles in their drawings of geometry lessons. A difference can be noted in the depictions of negative features; in the lower grades, it is mostly teachers shown in a negative mood, whereas in the higher grades it is students who are shown in a negative mood. A neutral classroom climate was the third least coded emotional state with $10 \%$ of drawings. Apart from Grade 4, where five students (15\% of drawings) depicted their geometry lessons as neutral, only two students (7\%-8\% of drawings) in Grades 3, 5, and 6 depicted their classroom climate as neutral. In all grades, almost all interviews confirmed this being a stable emotional condition in geometry lessons (trait). A standout difference can be seen regarding the percentage of negative emotional classroom climate. Among the third-graders, with one exception, no drawing was drawn with purely negative features. This single drawing, however, represented a state situation of emotion. None of the children in Grade 6 drew a picture with negative features. In Grades 4 and 5, three and two drawings, respectively, showed a negative classroom climate. With respect to the former, a state situation of emotion was revealed in the interviews, whereas the Grade 5 drawings represented a trait situation of emotion. Overall, the emotional classroom climate could not be identified in five drawings (1-2 drawings per grade level) as no identifying characteristics were either drawn or described. 
Thus, when comparing all four grade levels, it can be observed that the greatest difference concerns the distribution of positive and ambivalent classroom climates. There was no significant difference in the proportion of drawings rated as negative. This may be due, among other things, to the fact that the proportion of ambivalent drawings is higher in Grade 6 (i.e., a larger proportion of drawn individuals with negative features) than in Grades 3 to 5 .

\section{Discussion and conclusions}

In the last section, the key aspects of geometry education with respect to emotional classroom climate are discussed. Lastly, the limitations of the study are considered, and some possible future research directions are provided.

\subsection{Emotional classroom climate in primary grade geometry}

The study reported here focused on children's perceptions of the geometry classroom learning milieu from an emotional perspective (Evans et al., 2009). For this purpose, a coding manual was created by adding to an existing one (Zambo, 2006), and rated the drawings five emotional classroom climate categories as suggested by Laine et al. $(2013,2015,2020)$.

The results indicate that a positive emotional classroom climate is prevalent in geometry lessons in all primary grade levels as was also reported by Reindl and Hascher (2013). That there are no negative trait representations in the drawings is consistent with the findings of the study by Glasnović Gracin and Kuzle (2018). What is striking is the high percentage of drawings illustrating an ambivalent classroom climate in Grade 6, which is accompanied by a lower percentage of positive ones. Dahlgren Johansson and Sumpter (2010) reached a similar conclusion, and also noticed a decrease in positive emotions in Grade 5 compared to Grade 2. A possible explanation for this finding could be a child's optimism, which is much more pronounced in younger students than in older ones (Hasselhorn, 2005). In all grades, there were one to two drawings in which the emotional classroom climate was unidentifiable. This does not necessarily mean that these students did not know or were unable to draw their own or their classmates' emotions (Lucquet, 1913, 1923, in Anning \& Ring, 2004); it may be that these few students took the task less seriously, and saved time by generalizing the children drawn in the drawings. 
The lower percentage of drawings evaluated as positive as well as an increased percentage of ambivalent drawings in Grade 6 indicates a negative trend in the positive emotional classroom climate. However, it needs to be clarified whether this may be limited to geometry teaching only. With respect to mathematics teaching in general, clearer results exist for this trend. In the studies of Laine et al. (2013, 2015, 2020) the emotional climate was mainly positive in Grade 3 classrooms, and the emotional climate in Grade 5 more negative, although there were large differences between classrooms. Thus, the findings with respect to emotional classroom climate in primary grade geometry are largely consistent with the previously conducted studies in mathematics (Dahlgren Johansson \& Sumpter, 2010; Laine et al., 2013, 2015, 2020; Reindl \& Hascher, 2013). It may be that a negative trend in the positive emotional classroom climate is driving this phase of schooling in general (i.e., independent of the subject or subject-specific area).

The emotional classroom climate depicted in the drawings was strongly characterized by "affective" traits. According to the analysis of the interviews, only 16 out of 114 drawings (14\%) were characterized by "situational context-bound states" which can independent of their nature (positive and negative) directly influence the classroom climate (Hannula, 2012). Furthermore, another factor influencing the emotional classroom climate in mathematics classes is the teacher (e.g., Evans et al., 2009; Harrison et al., 2007). In almost all cases (ca. 90\%), the teacher was portrayed with positive or neutral features, which was confirmed in the interviews. From the interviews, it was clear that the teacher's admonitions or bad mood (e.g., yelling), had a negative influence on the students' emotional experience in geometry lessons which was also reported by Hannula (2012).

\subsection{Limitations of the study and future research directions}

This study was an exploratory qualitative study using purposive sampling with 114 students from two German federal states, and for that reason cannot be generalized to a broader population but is rather illustrative of other similar samples. These limitations suggest a possible next step in research, namely to conduct a study with a larger data sample in a wider variety of settings (e.g., federal states or countries) and using alternative sampling strategies (e.g., maximum variation sampling, probability sampling), so that a researcher could create a more thorough description of the perceptions students have of the emotional classroom climate in geometry lessons, which can then be generalizable to a population. In addition, drawings from entire 
classrooms across different grades and schools may provide a more holistic insight into the collective emotional climate in primary grade geometry lessons as was done in the work by Laine et al. (2013, 2015, 2020) and Tuohilampi et al. (2016). This would, in addition, allow for comparisons between different grades and schools. Since this was a cross-sectional study and for that reason, the development of emotional classroom climate could not be researched, in order to map the course of the emotional climate in the classroom, a longitudinal study from the beginning of school to the transition to secondary school of each individual reference group could be aimed at. Also, in further studies, other subareas of mathematics (e.g., arithmetic) could be examined more closely as well as differences in the emotional perceptions concerning these. Lastly, the study design did not allow the making of direct inferences between the students' perceptions of the emotional classroom climate in geometry and those of the teacher. The particular role of the teacher can be further explored in future research by using additional data sources, such as the teacher's drawing of a geometry lesson.

Drawings and the processes by which they are made have opened up a new way of gaining insight into students' perceptions of emotional classroom climate in primary grade geometry. Nevertheless, there were some drawbacks. The drawings showed considerable differences in quality. Due to the heterogeneous development in childhood, it is important to ensure that the children in the lowest grades are able to do what is required of them in terms of drawing (Billmann-Mahecha \& Drexler, 2010). Furthermore, the representations are strongly dependent on the motivation of the students. The drawings of Grade 5 and 6 students in particular were often very simple and could only be interpreted correctly by taking the interviews into consideration. It may be useful to see if this type of research matches the interests of this age group. By talking to participants before they begin the actual task, it could be established whether the respective child likes to draw, or more specific instructions or incentives could be given.

Despite the inventory, the analysis of the drawings has proven to be a challenging task. As Blumer (1969) noted, the analysis of drawings is understood as interpreting the meanings that the students had given to the situations and objects they had presented. Thus, in order to avoid the coder's own interpretation, not only analyst triangulation is needed, but also methodological triangulation such as participantproduced drawings (Kuzle \& Glasnović Gracin, 2020; Kearney \& Hyle, 2004). This allowed each student to interpret his or her drawing, which consequently allowed an 
in-depth understanding of what the child had drawn, and a more accurate representation of their experiences and emotions. Methodologically, the semistructured interview guide can be modified and extended, especially with regard to the "affective" state and trait. Furthermore, the coding manual developed by Zambo (2006) can be further developed. Here, each drawing offers new data and sometimes contains different characteristics, which should be recorded in the manual.

By relating the study results to teaching practice, some implications for geometry lessons can be drawn. After evaluating the results, it became apparent that the students experience quite different emotions in their geometry classrooms. These can be for instance positive, negative, short-term, or relatively stable. For practice, this means that everything that happens in the classroom, every statement, gesture, facial expression, and behavior can have a direct impact on the emotional classroom climate. Similarly, the teachers' actions in the classroom are instrumental in shaping students' attitudes toward mathematics (Harrison et al., 2007). If they evoke negative emotions in the students through their attitude, facial expressions, gestures, or behavior, it can have a detrimental effect on the students' attitudes toward mathematics instruction. Often, short-term emotions are related to the demands of mathematics instruction. It is particularly important that short-term negative emotions do not become entrenched. The lessons and the teacher's interaction with the students in the classroom must be reflected on regularly so that any problems can be quickly identified and remedied. Here, drawings may also be used as a method of evaluation and feedback (Borthwick, 2011). They help students to express themselves better and provide the teacher with an insight into how the students perceive the emotional classroom climate taking all protagonists into consideration. As such, students' drawings and their interpretations are productive ways of promoting dialogue about the working atmosphere (i.e., teaching and learning) between young people and their teachers (Anning \& Ring, 2004).

\section{References}

Ahtee, M., Pehkonen, E., Laine, A., Näveri, L., Hannula, M. S., \& Tikkanen, P. (2016). Developing a method to determine teachers' and pupils' activities during a mathematics lesson. Teaching Mathematics and Computer Science, 14(1), 25-43. https://doi.org/10.5485/tmcs.2016.0414 Anning, A., \& Ring, K. (2004). Making sense of children's drawings. Open University Press. Ashkanasy, N. M. (2003). Emotions in organizations: a multi-level perspective. In F. Dansereau \& F. J. Yammarino (Eds.), Multi-level issues in organizational behavior and strategy (Vol. 2, pp. 9-54). Emerald. https://doi.org/10.1016/S1475-9144(03)02002-2 
Backe-Neuwald, D. (2000). Bedeutsame Geometrie in der Grundschule: Aus Sicht der Lehrerinnen und Lehrer, des Faches, des Bildungsauftrages und des Kindes [Significant geometry in the primary school: From the viewpoint of the teachers, the subject, the educational mission, and the child] [Unpublished doctoral dissertation]. Universität Paderborn.

Billmann-Mahecha E. (2010). Auswertung von Zeichnungen [Evaluation of drawings]. In G. Mey \& K. Mruck (Eds.), Handbuch Qualitative Forschung in der Psychologie (pp. 707-722). VS Verlag für Sozialwissenschaften. https://doi.org/10.1007/978-3-531-92052-8_49

Blumer, H. (1969). Symbolic interactionism. Perspective and method. Prentice Hall.

Borthwick, A. (2011). Children's perceptions of, and attitudes towards, their mathematics lessons. British Society for Research into Learning Mathematics, 31, 37-42.

Clark, A. (2005). Listening to and involving young children: A review of research and practice. Early Child Development and Care, 175(6), 489-505. https://doi.org/10.1080/03004430500131288

Dahlgren Johansson, A., \& Sumpter, L. (2010). Children's conceptions about mathematics and mathematics education. In K. Kislenko (Ed.), Current state of research on mathematical beliefs XVI. Proceedings of the MAVI-16 Conference (pp. 77-88). Institute of Mathematics and Natural Sciences, Tallinn University.

Dohrmann, C., \& Kuzle, A. (2014). Unpacking children's angle “Grundvorstellungen”: The case of distance Grundvorstellung of $1^{\circ}$ angle. In P. Liljedahl, C. Nicol, S. Oesterkle, \& D. Allan (Eds.), Proceedings of the 38th Conference of the International Group for the Psychology of Mathematics Education and the 36th Conference of the North American Chapter of the Psychology of Mathematics Education (Vol. 2, pp. 409-416). PME.

Eder, F. (Ed.). (1995). Bildungsforschung des Bundesministeriums für Unterricht und Kulturelle Angelegenheiten. Das Befinden von Kindern und Jugendlichen in der Schule:

Forschungsbericht im Auftrag des BMUK [Educational research of the Federal Ministry for Education and Cultural Affairs. The well-being of children and adolescents at school: research report commissioned by the BMUK]. Studien-Verlag.

Eichler, K.-P. (2005). Zum Geometrieunterricht in der Grundschule [On teaching geometry in the primary school]. Grundschulunterricht, 52(11), 2-6.

Einarsdóttir, J. (2007). Research with children: methodological and ethical challenges. European Early Childhood Education Research Journal, 15(2), 197-211.

https://doi.org/10.1080/13502930701321477

Evans, I. M., Harvey, S. T., Buckley, L., \& Yan, E. (2009). Differentiating classroom climate concepts: academic, management, and emotional environments. Kotuitui: New Zealand Journal of Social Sciences Online, 4(2), 131-146.

https://doi.org/10.1080/1177083x.2009.9522449

Frenzel, A., \& Stephens, E. (2017). Emotionen [Emotions]. In T. Götz (Eds.), Emotion, Motivation und selbstreguliertes Lernen (2nd ed., pp. 15-77). Verlag Ferdinand Schöningh.

Glasnović Gracin, D., \& Kuzle, A. (2018). Drawings as external representations of children's mathematical ideas and emotions in geometry lessons. Center for Educational Policy Studies Journal, 8(2), 31-53. https://doi.org/10.26529/cepsj.299

Götz, T., Zirngibl, A., \& Pekrun, R. (2011). Lern- und Leistungsemotionen von Schülerinnen und Schülern [Learning and achievement emotions of students]. In T. Hascher (Ed.), Schule positiv erleben Erkenntnisse und Ergebnisse zum Wohlbefinden von Schülerinnen und Schülern (pp. 49-66). Haupt AG.

Gramel, S. (2008). Die Darstellung von guten und schlechten Beziehungen auf Kinderzeichnungen: Zeichnerische Differenzierung unterschiedlicher Beziehungsqualitäten 
[The representation of good and bad relationships in children's drawings: Drawing differentiation of different relationship qualities]. Verlag Dr. Kovač.

Hannula, M. S. (2012) Exploring new dimensions of mathematics-related affect: embodied and social theories. Research in Mathematics Education, 14(2), 137-161.

https://doi.org/10.1080/14794802.2012.694281

Harrison, L. J., Clarke, L., \& Ungerer, J. A. (2007). Children's drawings provide a new perspective on teacher-child relationship quality and school adjustment. Early Childhood Research Quarterly, 22(1), 55-71. https://doi.org/10.1016/j.ecresq.2006.10.003

Hascher, T., \& Edlinger, H. (2009). Positive Emotionen und Wohlbefinden in der Schule - ein Überblick über Forschungszugänge und Erkenntnisse [Positive emotions and well-being in the school - a review of research approaches and findings]. Psychologie in Erziehung und Unterricht, 56(2), 105-122.

Hascher, T., Hagenauer, G., \& Albrecht-Schaffer, A. (2011). Wohlbefinden in der Grundschule [Well-being in elementary school]. Erziehung und Unterricht, 161(3-4), 381-392.

Hasselhorn, M. (2005). Lernen im Altersbereich zwischen 4 und 8 Jahren: individuelle Voraussetzungen, Entwicklung, Diagnostik und Förderung [Learning in the age range between 4 and 8 years: individual preconditions, development, diagnostics and support]. In T. Guldimann \& B. Hauser (Eds.), Bildung 4- bis 8-jähriger Kinder (pp. 77-88). Waxmann. Helmke, A. (1993). Die Entwicklung der Lernfreude vom Kindergarten bis zur 5. Klassenstufe [Developing learning-eagerness from kindergarten through $5^{\text {th }}$ grade]. Zeitschrift für Pädagogische Psychologie, 7, 77-86.

Hill, M. (1997). Participatory research with children. Child and Family Social Work, 2, 171-183. https://doi.org/10.1046/j.1365-2206.1997.00056.x

Kearney, K. S., \& Hyle, A. (2004). Drawing out emotions: the use of participant-produced drawings in qualitative inquiry. Qualitative Research, 4(3), 361-382.

https://doi.org/10.1177/1468794104047234

Krauthausen, G. (2018). Einführung in die Mathematikdidaktik - Grundschule [Introduction to mathematics didactics - Elementary school]. Springer Spektrum. https://doi.org/10.1007/978-3-662-54692-5

Kuzle, A., \& Glasnović Gracin, D. (2020). Making sense of geometry education through the lens of fundamental ideas: An analysis of children's drawing. The Mathematics Educator, 29(1), 752.

Laine, A., Ahtee, M., \& Näveri, L. (2020). Impact of teacher's actions on emotional atmosphere in mathematics lessons in primary school. International Journal of Science and Mathematics Education, 18, 163-181. https://doi.org/10.1007/s10763-018-09948-x

Laine, A., Ahtee, M., Näveri, L., Pehkonen, E., Koivisto, P. P., \& Tuohilampi, L. (2015). Collective emotional atmosphere in mathematics lessons based on Finnish fifth graders' drawings. LUMAT: International Journal on Math, Science and Technology Education, 3(1), 87-100. https://doi.org/10.31129/lumat.v3i1.1053

Laine, A., Näveri, L., Ahtee, M., Hannula, M. S., \& Pehkonen, E. (2013). Emotional atmosphere in third-graders' mathematics classroom - an analysis of pupils' drawings. Nordic Studies in Mathematics Education, 17(3-4), 101-116.

Neuß, N. (2014). Kinderzeichnungen in der medienpädagogischen Forschung [Children's drawings in media education research]. In A. Tillmann, S. Fleischer S., \& K.-U. Hugger (Eds.), Handbuch Kinder und Medien. Digitale Kultur und Kommunikation (Vol. 1, pp. 247-258). Springer VS. https://doi.org/10.1007/978-3-531-18997-0_19

Nossiter, V., \& Biberman, G. (1990). Projective drawings and metaphor: Analysis of organisational culture. Journal of Managerial Psychology, 5(3), 13-16.

Patton, M. Q. (2002). Qualitative research and evaluation methods (3rd ed.). Sage. 
Punch, S. (2002). Research with children the same or different from research with adults? Childhood, 9(3), 321-341. https://doi.org/10.1177/0907568202009003005

Reindl, S., \& Hascher, T. (2013). Emotionen im Mathematikunterricht in der Grundschule [Emotions in the teaching of mathematics in the primary school]. Unterrichtswissenschaft, 41(3), 268-288.

Schiepe-Tiska, A., \& Schmidtner, S. (2012). Mathematikbezogene emotionale und motivationale Orientierungen, Einstellungen und Verhaltensweisen von Jugendlichen in PISA 2012 [Mathematics-related emotional and motivational orientations, attitudes, and behaviors of adolescents in PISA 2012]. In M. Prenzel, C. Sälzer, E. Klieme, \& O. Köller (Eds.), PISA 2012. Fortschritte und Herausforderungen in Deutschland (pp. 99-122). Waxmann.

Schmude, C. (2005). Differenzielle Entwicklungsverläufe der Lernfreude im Grundschulalter [Differential developmental trajectories of learning-eagerness in primary school age]. Humboldt-Universität zu Berlin. https://doi.org/10.18452/9291

Thomson, P. (2008). Children and young people: Voices in visual research. In P. Thompson (Ed.), Doing visual research with children and young people (pp. 1-20). Routledge.

Tuohilampi, L., Laine, A., Hannula, M. S., \& Varas, L. (2016). A comparative study of Finland and Chile: the culture-dependent significance of the individual and interindividual levels of the mathematics-related affect. International Journal of Science and Mathematics Education, 14, 1093-1111. https://doi.org/10.1007/s10763-015-9639-0

van Ophuysen, S. (2008). Zur Veränderung der Schulfreude von Klasse 4 bis 7 [On the change in school enjoyment from Grades 4 to 7]. Zeitschrift für Pädagogische Psychologie, 22(34), 293-306. https://doi.org/10.1024/1010-0652.22.34.293

Veale, A. (2005). Creative methodologies in participatory research with children. In S. Greene \& D. Hogan (Eds.), Researching children's experience (pp. 253-273). Sage.

vom Hofe, R., Pekrun, R., Kleine, M., \& Götz, T. (2002). Projekt zur Analyse der Leistungsentwicklung in Mathematik (PALMA). Konstruktion des Regensburger Mathematikleistungstests für 5.-10. Klassen [Project on the analysis of the performance development in mathematics (PALMA). Construction of the Regensburg mathematics achievement test for Grades 5-10]. In M. Prenzel \& J. Doll (Eds.), Bildungsqualität von Schule: Schulische und außerschulische Bedingungen mathematischer, naturwissenschaftlicher und überfachlicher Kompetenzen (pp. 83-100). Beltz Verlag.

Weber, S. J., \& Mitchell, C. (1995). 'That's funny, you don't look like a teacher': Interrogating images, identity, and popular culture. The Falmer Press.

Zambo, D. (2006). Using thought-bubble pictures to assess students' feelings about reading. The Reading Teacher, 59(8), 798-803. https://doi.org/10.1598/rt.59.8.7 